Running Head: BIG FIVE AND GENERALIZED PREJUDICE

Who is Prejudiced, and Towards Whom? The Big Five Traits and Generalized Prejudice Jarret T. Crawford

The College of New Jersey

Mark J. Brandt

Tilburg University

In press, Personality and Social Psychology Bulletin

Corresponding author:

Jarret T. Crawford

Psychology Department

The College of New Jersey

2000 Pennington Rd

Ewing, NJ 08628

crawford@tcnj.edu

(609) 771-2117 
BIG FIVE AND GENERALIZED PREJUDICE 2

\begin{abstract}
Meta-analyses show that low levels of Openness and Agreeableness correlate with generalized prejudice. However, previous studies narrowly assessed prejudice toward low status, disadvantaged groups. Using a broad operationalization of generalized prejudice towards a heterogeneous array of targets, we sought to answer two questions: a) Are some types of people prejudiced against most types of groups, and b) Are some types of people prejudiced against certain types of groups? Across four samples $(\mathrm{N}=7,543)$, Openness was very weakly related to broad generalized prejudice, $r=-.03$, 95\%CI [-.07, -.001], whereas low Agreeableness was reliably associated with broad generalized prejudice ( $r=-.23,95 \%$ CI [-.31, -.16]). When target characteristics moderated relationships between Big Five traits and prejudice, they implied that perceiver-target dissimilarity on personality traits explain prejudice. Importantly, the relationship between Agreeableness and prejudice remained robust across target groups, suggesting it is the personality trait orienting people toward (dis)liking of others.
\end{abstract}

Keywords: Big Five; Agreeableness; Openness; prejudice; generalized prejudice 
BIG FIVE AND GENERALIZED PREJUDICE 3

\section{Who is Prejudiced, and Towards Whom? The Big Five Traits and Generalized Prejudice}

In The Nature of Prejudice, Allport (1954, p. 68) wrote of the “prejudiced personality,” noting, "One of the facts of which we are most certain is that people who reject one out-group will tend to reject other out-groups. If a person is anti-Jewish, he is likely to be anti-Catholic, anti-Negro, anti any out-group.” Allport (pp. 396; 431) also identified a number of personality traits and individual differences (mostly derived from work on the authoritarian personality; Adorno, Frenkel-Brunswik, Levinson, \& Sanford, 1950) associated with the prejudiced personality, including psychological rigidity, fearfulness, and political conservatism. From this perspective, some people are simply predisposed to be more prejudiced than others, and toward most types of groups.

Modern scholars have investigated the prejudiced personality (now referred to as generalized prejudice) by examining how variation in prejudice toward multiple groups is associated with basic personality traits, such as those identified by the Big Five personality theory (e.g., Costa \& McCrae, 1985). ${ }^{1}$ Low Openness and Agreeableness are consistently and robustly associated with target-specific prejudice (i.e., racism, sexism, anti-immigrant or antiforeigner attitudes; e.g., Flynn, 2005; van Hiel \& Mervielde, 2004) and generalized prejudice across several target groups (e.g., Ekehammar \& Akrami, 2003; Ekehammar, Akrami, Gylje, \& Zakrisson, 2004), with meta-analytic effect size estimates of -.30 and -.22, respectively (Sibley \& Duckitt, 2008). These relationships are thought to reflect preferences for normativity and conformity among those low in Openness, and tough-mindedness among those low in Agreeableness (e.g., Sibley \& Duckitt, 2008; see also Graziano et al., 2007, who argue that those

\footnotetext{
${ }^{1}$ Openness (curious and imaginative vs. closed-minded and simple), Conscientiousness (organized and responsible vs. disorganized and careless), Extraversion (outgoing and talkative vs. reserved shy), Agreeableness (sympathetic and cooperative vs. rude and hostile), and Neuroticism (anxious and fearful vs. calm and stable).
} 
BIG FIVE AND GENERALIZED PREJUDICE 4

low in Openness are less attuned to prejudice-suppressing norms). The other three Big Five factors do not have the same consistent relationships. The relationship between Extraversion and prejudice was significantly different from zero, but small $(r=-.07)$, and there were no significant meta-analytic effects of Conscientiousness $(r=.02)$ or Neuroticism $(r=-.01)$ on prejudice (Sibely \& Duckitt, 2008). Subsequent research has replicated the effects of Openness and Agreeableness on generalized prejudice (Akrami, Ekehammar, \& Bergh, 2011; Akrami, Ekehammar, Bergh, Dahlstrand, \& Malmsten, 2009; Bergh, Akrami, \& Ekehammar, 2012; see Hodson \& Dhont, 2015 for a review), suggesting that low Openness and Agreeableness are the personality underpinnings of generalized prejudice. We put that conclusion to a strong test in this paper.

\section{Narrow vs. Broad Generalized Prejudice}

One problem that prevents drawing such a strong conclusion is that generalized prejudiced is operationalized in a narrow way — towards low status, disadvantaged, and unconventional target groups. For example, common measures of generalized prejudice includes prejudice against racial minorities, women, gay men and lesbians, and the disabled (Ekehammar \& Akrami, 2003; 2007; Ekehammar et al., 2004). Others include attitudes toward women, immigrants, the disabled, and gay men and lesbians (Akrami et al., 2011; Akrami et al., 2009; Bergh et al., 2012). The key factor that appears to tie these groups together, and therefore underlies generalized prejudice research, is the low status of the target groups (Bergh, Akrami, Sidanius, \& Sibley, 2016).

Although there are clear moral and societal reasons to focus on prejudice towards low status groups, low status groups are just one end of one dimension on which people perceive groups (Cuddy, Fiske, \& Glick, 2008; Koch, Imhoff, Dotsch, Unkelbach, \& Alves, 2016). 
BIG FIVE AND GENERALIZED PREJUDICE 5

Moreover, people can express prejudice against more than just low status groups. Prejudice is “a negative evaluation of a group or of an individual on the basis of group membership” (Crandall, Eshleman, \& O’Brien, 2002, p. 359). Indeed, as Aronson, Wilson, and Akert (2010, p. 388) note, "Prejudice is a two-way street; it often flows from the minority group to the majority group as well as in the other direction. And any group can be a target of prejudice." (emphasis ours; for similarly broad definitions, see Brandt \& Proulx, 2016; Brown, 2010). Any measure of generalized prejudice can only generalize to the groups that the measure samples. Most research has sampled low status groups; we extend the sample to include a broader population of social groups, towards what we refer to as broad generalized prejudice, which assesses prejudice to a heterogeneous array of target groups.

Our first purpose therefore was to estimate the relationships between each Big Five trait and broad generalized prejudice, and to compare and contrast these relationships to those obtained using a measure of narrow generalized prejudice. Doing so allows us to test whether some people are prejudiced against most groups, or whether previous findings are an artefact of the types of target groups typically assessed. This includes not only Openness and Agreeableness, but also the other Big Five factors, as the narrow focus of previous generalized prejudice research may have obscured their import. We analyzed data from four samples (total $\mathrm{N}$ $=7,543$ ). Sample 1 was drawn from the American National Election Survey (ANES), and Samples 2 - 4 were drawn from Mechanical Turk. Each sample included a measure of the Big Five traits and measures of prejudice against a wider range of targets than used in previous generalized prejudice research. We meta-analyze the findings across these four samples to address this first research question. Doing so will allow us to compare and contrast the Big Five traits that are associated with narrow vs. broad generalized prejudice and give us insight into 
BIG FIVE AND GENERALIZED PREJUDICE 6

whether findings about narrow generalized prejudice extend to findings about broad generalized prejudice.

This broad generalized prejudice approach can therefore distinguish between whether there are some personality types that predispose people to disliking of others (as implied by research using a narrow approach to generalized prejudice), or whether previously observed relationships are dependent on the types of groups studied. Below, we explore why the personality-prejudice relationship might depend on the types of groups studied.

\section{Are Some Types of People Prejudiced Against Certain Types of Groups?}

Our second purpose was to determine whether the observed relationships between Big Five traits and prejudice are moderated by target group characteristics. If there is a difference in the personality underpinnings of narrow and broad generalized prejudice (i.e., if Openness and/or Agreeableness do not predict broad generalized prejudice), we can uncover why there might be differences between the two operationalizations of generalized prejudice by understanding what group characteristics moderate the associations between personality and prejudice towards individual groups. This will tell us if there are some types of people who are prejudiced against certain types of groups. Such an approach is consistent with an interactionist perspective that recognizes that certain intergroup contexts will affect how personality influences attitudes.

We start with the presumption that the types of groups often considered in generalized prejudice research are fairly homogeneous_-e.g., low status, socially disadvantaged, and politically liberal (cf. Brandt, Reyna, Chambers, Crawford, \& Wetherell, 2014). When considering a more heterogeneous array of targets, it opens up the possibility to examine whether some types of traits relate to prejudice toward some particular types of target groups. Indeed, we are not aware of any work systematically examining the types of groups for whom certain 
personality traits predict more or less prejudice. We selected five different group characteristics that may moderate the association between personality traits and prejudice based on prior relevant work on group perceptions.

Specifically, we looked at group characteristics known to be fundamental to social judgment, along with characteristics we thought might serve as markers of perceiver-target dissimilarity, given the central role of perceived dissimilarity in prejudice (e.g., Brandt et al., 2014). Work by Cuddy et al. (2008) and Koch et al. (2016) indicate that perceived status, warmth, and ideology are all fundamental dimension of social judgment which people use to spontaneously categorize and stereotype groups (Cuddy et al., 2008; Koch et al., 2016). Further, Weiner and colleagues (e.g., Weiner, 1995; Weiner, Perry \& Magnusson, 1988) show that choice and responsibility are important factors in prejudice and other social judgment. Therefore, target variation in such characteristics is likely to affect the association between personality traits and prejudice. The precise group characteristic that matters likely depends on the personality trait in question. Status appears likely to moderate the association between Agreeableness and prejudice, likely because of the association between Agreeableness and social dominance orientation (e.g., Sibley \& Duckitt, 2008). Warmth also seems likely to moderate the association between Agreeableness and prejudice because interpersonal warmth is inherent to the Agreeableness construct (Parks-Leduc et al., 2015). For example, one study finds that people high in Agreeableness more negatively evaluated targets who engage in antisocial behavior than people low in Agreeableness, above and beyond the effects of perceived similarity with the target (Kammrath \& Scholer, 2011). Perceived ideology appears likely to moderate the association between both Openness and Conscientiousness and prejudice because both traits are associated with political beliefs (e.g., high Openness and low Conscientiousness are associated with 
BIG FIVE AND GENERALIZED PREJUDICE 8

political liberalism; Fatke, 2017; Hirsh, DeYoung, Xu, \& Peterson, 2010) and people tend to be prejudice towards people with dissimilar political beliefs (Brandt et al., 2014). Finally, perceived choice of group membership was included in this research because prejudice against low status groups is related to perceptions that those group members have little choice over their group membership (Keller, 2005; see also Jayaratne et al., 2006; Keller, 2005; Suhay, Brandt, \& Proulx, 2017; Williams \& Eberhardt, 2008). Given its relationship to prejudice against low status groups, Agreeableness may be associated with prejudice against groups with little membership choice. Further, people with lower levels of cognitive ability tended to express more prejudice towards groups who were perceived as not having a choice of group membership (Brandt \& Crawford, 2016).

Finally, we also included perceived assertiveness as a potential moderator, as assertiveness is inherent to the Extraversion construct (Parks-Leduc, Feldman, \& Bardi, 2015). ${ }^{2}$ It may be that people low on Extraversion are more prejudiced towards groups they see as assertive because people tend to dislike people and groups they disagree with or are dissimilar to (Brandt et al., 2014; Byrne, 1969).

\section{Overview of the Present Studies}

This research seeks to address whether certain types of people are prejudiced against most groups, and whether certain types of people are prejudiced against particular types of groups. To address our first question, we first report data from four separate samples of the relationship between Big Five traits and prejudice toward heterogeneous sets of targets. We report these relationships meta-analytically for both broad and narrow generalized prejudice. Doing so allows us to compare and contrast between different approaches to this question. To

\footnotetext{
${ }^{2}$ Note that we had no a priori predictions for which if any characteristics might moderate the Neuroticism-prejudice relationship, and did not select any to explicitly test moderation of that relationship.
} 
BIG FIVE AND GENERALIZED PREJUDICE 9

address our second question, we then meta-analytically examine whether characteristics associated with these targets (collected in a separate fifth sample) moderated the relationships between Big Five traits and prejudice observed across the four samples. Doing so allows us to determine whether there are certain group characteristics that draw out prejudice from people who vary in their personality traits.

\section{Samples 1 - 4: Correlations between Big Five Traits and Prejudice}

\section{Participants}

Sample 1 was drawn from the 2012 American National Election Studies (ANES) timeseries study, which included a large, nationally representative sample of American adults using a pre/post-election design. The ANES sample included 5,914 participants, of whom 5,510 completed both the pre- and post-measures (52\% female; modal age group 55-59 years; 59\% White) (sample sizes vary in our analyses because of missing or incomplete responses on some of our key variables).

The disadvantage of this nationally representative sample is that we were unable to select target groups for inclusion. We therefore collected three community samples using Mechanical Turk. Samples 2 and 3 used targets drawn from previous studies that used targets selected for their ideological heterogeneity (i.e., Chambers, Schlenker, \& Collisson, 2013; Crawford \& Pilanski, 2014; Wetherell et al., 2013). Sample 4 used the 16 groups that participants in Koch et al.'s (2016) Study 5a mentioned at least $20 \%$ of the time during a bottom-up stimuli generation task. Thus, these groups are ones that people generated when asked to think about social groups and cannot be biased by the group selection choices of the researchers. (Sample 2: $\mathrm{N}=617,47 \%$ women, $M_{\text {age }}=33$ years, $76 \%$ White; Sample 3: $N=509,50 \%$ women, $M_{\text {age }}=35$ years, $74 \%$ 
BIG FIVE AND GENERALIZED PREJUDICE 10

White; Sample 4: $\mathrm{N}=503,50 \%$ women, $M_{\text {age }}=37$ years, $76 \%$ White). Each sample had at least $90 \%$ power to detect an effect of $r=.15$

\section{Procedure}

In Samples 1, 2, and 3, prejudice was measured before personality. In Sample 4, personality was measured before prejudice. In Sample 1, item order within the personality and prejudice measures was fixed. In Samples 2 -4, item order within the personality and prejudice measures was randomized.

\section{Materials}

All materials are available at: https://osf.io/kj98v/

Personality. In Samples 1 and 2, the Big Five factors were measured with the ten-item personality inventory (TIPI; Gosling, Rentfrow, \& Swann, 2003), which includes two items per trait, with one word pair intended to capture the trait (e.g., "extraverted, enthusiastic” for Extraversion) and another word pair contrary to the trait (e.g., "reserved, quiet” for Extraversion, reverse-coded). In Sample 1, participants were asked how well each word pair described them (1 = extremely poorly; 7 = extremely well). In Sample 2, participants were asked to indicate the extent to which they agreed that the word pair described them $(1=$ disagree strongly; $7=$ agree strongly). Responses to the two items were averaged together to form each trait measure (Study 1: extraversion $r=.30$; agreeableness $r=.17$; conscientiousness $r=.37$; neuroticism $r=.37$; openness $r=.24$; Study 2: extraversion $r=.60$; agreeableness $r=.29$; conscientiousness $r=.49$; neuroticism $r=.65$; openness $r=.36$ ).

Because the TIPI may not be able to capture the depth of personality facets, in Samples 3 and 4, we used the 44-item Big Five Inventory (John \& Srivistava, 1999) to generalize the results of Studies 1 and 2 with an expanded Big Five measure. The BFI has been used in previous 
research on personality and generalized prejudice (Ekehammar, Akrami, Gylje, \& Zakrisson, 2004). Participants indicated the extent to which they agreed that the trait items applied to them (1 = Disagree strongly; 5 = Agree strongly). Cronbach’s alphas for the five scales ranged from .83 to .89 . Table S1 reports the bivariate correlations among the Big Five traits in Samples $1-4$. Prejudice. We assessed prejudice against 24, 20, 10, and 16 targets in Samples 1 - 4, respectively. ${ }^{3}$ Each sample included a feeling thermometer rating $(0=$ very cold/unfavorable; 100 = very warm/favorable) (reverse-coded) toward each target. Although feeling thermometers are some of the most widely used prejudiced measures (Correll et al., 2010), we included additional measures of target antipathy in Samples 3 and 4. Social distance is another common prejudice measure (Correll et al., 2010), and so was also included in Samples 3 and 4 (1 = Very unwilling; 6 = Very willing; reverse-scored). In Sample 3, social distance was measured with three items: "How willing or unwilling would you be to have someone from each of the following groups 1) come work in the same place as you do; 2) marry into your family; 3) as a close personal friend.” In Sample 4, social distance was measured with the item, “How willing would you be to occasionally spend social time with a person who is a member of the following groups?” Feeling thermometer and social distance ratings were highly correlated with each other (Sample 3: rs ranged from .40 to .77; Sample 4: rs ranged from .51 to .74). We therefore converted these two measures to scales ranging from 0 to 1 , and combined them to create the prejudice measure (for a similar approach, see Crawford, Brandt, Inbar, Chambers, \& Motyl, 2017). Sample 4 also included a measure of political intolerance (Marcus, Sullivan, Theiss-

\footnotetext{
${ }^{3}$ We assessed considerably fewer groups in Samples 3 and 4 because these samples also included target group characteristic ratings in addition to prejudice ratings, thus necessitating reducing the number of groups assessed to attenuate participant fatigue. Sample 4 also included measures of the intergroup emotions of pride, disgust, envy, and pity (Fiske, Cuddy, Glick, \& Xu, 2002) toward each group, but analyses are not reported here. Data are available on the OSF.
} 
Morse, \& Wood, 1995; "I think that members of this group should not be allowed to distribute pamphlets and other materials on local college campuses;” $1=$ Strongly Disagree; 7 = Strongly Agree), which was not highly correlated with prejudice (rs ranged from .05 to .23) and so was treated as a separate outcome.

Broad generalized prejudice was measured by averaging prejudice ratings across all groups. To measure narrow generalized prejudice, we limited analyses to targets included in previous generalized prejudice research (feminists; gay men and lesbians; Muslims; people on welfare; poor people; Blacks; Asians; Hispanics; illegal immigrants; unemployed people; elderly people; transgender people; Akrami et al, 2011; Bergh et al. 2012; Duckitt \& Sibley, 2007; Ekehammar \& Akrami, 2003). These targets are italicized in Tables S2 - S6.

Sample 4 also included feeling thermometer ratings of frogs and robots. Although robots and frogs are not the typical targets of prejudice, their inclusion allows us to examine whether Agreeableness ${ }^{4}$ was associated with negative interpersonal or intergroup attitudes specifically, or simply negative appraisals generally, even toward non-human entities (for their use as targets in prior social cognition research, see e.g., Gray, Gray, \& Wegner, 2007).

\section{Relationships Between Big Five Traits and Broad and Exclusive Generalized Prejudice ${ }^{5}$}

To estimate the size of the effects of each Big Five personality trait on generalized prejudice, we meta-analyzed the results from the four samples. We estimated the models using the “rma.uni” function from R’s “metafor" package (Viechtbauer, 2010) and specified randomeffects models with narrow maximum-likelihood (REML) estimators. Consistent with past

\footnotetext{
${ }^{4}$ These was included in Sample 4 because the previous samples (Samples 1 - 3) showed robust relationships between Agreeableness and broad generalized prejudice.

${ }^{5}$ Tables S2 - S5 present the relationships between Big Five traits and prejudice for each target for Samples 1 - 4, respectively, and Table S6 presents the relationships between Big Five traits and political intolerance for each target for Sample 4. Table S7 reports the relationships between Big Five traits and inclusive and restricted generalized prejudice and political intolerance.
} 
BIG FIVE AND GENERALIZED PREJUDICE 13

research (e.g., Ekehammar \& Akrami, 2007), we focus on the partial correlations between each trait and prejudice while controlling for the other four traits. Figure 1 displays the forest plots for the meta-analyses of the partial correlations between each of the Big Five traits and generalized prejudice. The left-most panel displays results for narrow generalized prejudice, and the rightmost panel displays results for broad generalized prejudice. Because it was only available for one sample, political intolerance was not included (see Table S6 for results regarding political intolerance).

Narrow generalized prejudice. We replicate findings typically reported in the literature. The effects of Agreeableness $(p r=-.25, z=-6.06, p<.001)$ and Openness $(p r=-.17, z=-11.04$, $p<.001)$ were significantly different from zero. Extraversion $(p r=-.03, z=-2.10, p=.04)$ and Conscientiousness ( $p r=.08, z=4.76, p<.001)$ were also significantly different from zero, but with small effects. The effect of Neuroticism ( $p r=-.09, z=-1.86, p=.06)$ was not significant. Our observed meta-analytic effect for Agreeableness is quite similar to the $r=-.22$ reported in Sibley and Duckitt (2008)'s meta-analysis, which also used a narrow operationalization of generalized prejudice. Our effect for Openness is lower than the $r=-.30$ reported in their metaanalysis, but this might be due to the use of the NEO-P-IR in several of the samples in the Sibley and Duckitt (2008) meta-analysis, which yields larger Openness-prejudice relationships than other Openness measures because of scale content overlap (see Sibley \& Duckitt, 2008, p. 267).

Broad generalized prejudice. Results notably diverged from those in the literature. Although the association between Agreeableness and broad generalized prejudice is similar to Agreeableness's association with narrow generalized prejudice $(p r=-.23, z=-6.19, p<.001)$, the effect of Openness is tiny $(p r=-.03, z=-2.07, p=.04)$. To put this tiny effect into perspective, to have $80 \%$ power to detect the estimated Openness effect a researcher needs 
approximately 6,666 participants. To have 50\% power, she needs 3,263 participants. The effects of Conscientiousness $(p r=.02, z=1.42, p=.16)$, and Neuroticism $(p r=-.002, z=-.08, p=.93)$ were not significantly different from zero and the effect of Extraversion $(p r=-.09, z=-5.21, p<$ .001) is small. Thus, among the Big Five traits, only low Agreeableness is robustly associated with broad generalized prejudice. Together, these results suggest a role of Openness when using a narrow operationalization of generalized prejudice that does not emerge under a broad operationalization.

Notably, the Agreeableness-prejudice relationship is unlikely due to a general negativity bias among people low in Agreeableness (or positivity bias among those high in Agreeableness). In Sample 4, Agreeableness was unrelated to "prejudice” ratings of frogs, $r(480)=.04, p=.462$, and was weakly and positively related to "prejudice" ratings of robots, $r(483)=.09, p=.041$ (this weak positive relationship is opposite of what one would expect if low Agreeableness is associated with a general negativity bias).

The results for broad and narrow generalized prejudice clearly differ, showing that any measure of generalized prejudice can only generalize to the groups that the measure samples. This suggests that the prejudiced personality will appear more or less generalizable depending on the breadth of groups included in the measure. When it is narrow, Agreeableness and Openness both have clear effects (consistent with prior work). When it is broad, only Agreeableness has a clear effect and the effect of Openness is nearly zero. One straightforward explanation for this difference is that the relationship between Openness and prejudice differs for each target group. Tables S2 - S5, which report the trait-prejudice correlations for each group, show that there is substantial variability. For example, sometimes Openness is negatively associated with prejudice (e.g., in the case of Gays and Lesbians) and sometimes Openness is positively associated with 
BIG FIVE AND GENERALIZED PREJUDICE 15

prejudice (e.g., in the case of Christian Fundamentalists). That is, personality traits might not be associated with a prejudiced personality per se (i.e. prejudice towards all/most groups), but rather prejudice towards particular types of groups (e.g., low vs. high status, conservative vs. liberal). We turn to this question next.

\section{Moderation of Personality-Prejudice Relationships by Target Characteristics}

We were next interested in what factors (if any) moderate the relationships between Big Five traits and prejudice towards individual target groups. To examine this question, we fielded a separate Mechanical Turk sample (Sample 5; $n=127)$. In our experience, approximately 100 participants give stable mean ratings of target group characteristics (e.g., Brandt, 2017; Brandt \& Crawford, 2016). Participants evaluated each of the 49 unique targets included in Samples $1-4$ on five characteristics (perceived social status, perceived warmth toward others, perceived ideology, perceived choice of group membership, and perceived assertiveness). ${ }^{6}$ All characteristics were measured on 100-point scales. Item wording for perceived social status, perceived ideology, and perceived choice were drawn from Brandt and Crawford (2016). See supplemental materials for item wording for each characteristic.

We followed the procedure used in Brandt and Crawford (2016) to test moderation of the personality-prejudice relationships by target characteristics. Specifically, collapsing across all four samples, we correlated the personality-prejudice pr coefficients from Samples 1 - 4 (i.e., those reported within parentheses in Tables S2 - S5) with the perceived status, warmth, ideology, choice, and assertiveness of each group as observed in Sample 5. We also performed

\footnotetext{
${ }^{6}$ Sample 3 also included measures of perceived conventionality, assertiveness, and warmth, and Sample 4 included measures of perceived status and ideology. Analyses of these moderation effects are included in SOM, and do not alter the conclusions of the analyses reported here.
} 
multiple regression analyses ${ }^{7}$ in which we regressed the personality-prejudice $p r$ coefficients from Samples 1 - 4 on each moderator simultaneously, along with dummy-coded sample variables. This allows us to examine the effect of each moderator on the personality-prejudice relationship independent of sample and of the other four moderators. Together, these analyses allow us to determine whether the strength of the personality-prejudice relationships depend on levels of the perceived characteristic (i.e., moderation). Bivariate correlation coefficients and standardized regression coefficients from all analyses are reported in Table 1 and displayed in Figure 2. We describe these relationships derived from the multiple regression analyses below, and synthesize and make sense of them in the Discussion.

Openness. There was a positive effect of perceived ideology; low Openness was associated with prejudice toward more liberal targets, and high Openness toward more conservative targets. There was also a smaller positive effect of perceived assertiveness, such that low Openness was associated with prejudice toward less assertive targets, and high Openness toward more assertive targets. We discount the significant effect of status, as it appears to be a suppression effect (i.e., the sign of the relationship reversed from the bivariate to the multivariate analyses).

Conscientiousness. There was a negative effect of perceived ideology; low Conscientiousness was associated with prejudice toward more conservative targets, and high Conscientiousness toward more liberal targets. We discount the significant effect of warmth, as it appears to be a suppression effect.

\footnotetext{
${ }^{7} \mathrm{We}$ also regressed the personality-prejudice $\mathrm{pr}$ coefficients on each moderator (without controlling for the other four moderators) and the dummy-coded sample variables. However, these were nearly identical to the bivariate relationships, so we do not report them here.
} 
Extraversion. There were negative effects of both status and ideology; low Extraversion was associated with prejudice toward higher status and more conservative targets, and high Extraversion toward lower status and more liberal targets.

Agreeableness. There were positive effects of status and choice, and a negative effect of warmth; low Agreeableness was associated with prejudice toward lower status, lower choice, and more warm targets, whereas high Agreeableness was associated with prejudice toward higher status, higher choice, and less warm targets. Despite these significant moderation effects, Figure 2 shows that these moderators did not really change the direction or nature of the main effect of Agreeableness on prejudice, as the regression line is nearly always below the zero point. We discount the significant effects of ideology and assertiveness, as they appear to be suppression effects.

Neuroticism. There was a positive effect of ideology and a negative effect of warmth; low Neuroticism was associated with more prejudice toward more liberal and more warm targets, whereas high Neuroticism was associated with more prejudice toward more conservative and less warm targets.

\section{Discussion}

In this paper, we address two related, but distinct unanswered questions about the longstudied relationship between personality and prejudice: What types of people will express prejudice toward most types of groups, versus what types of people will express prejudice toward certain types of groups? To do so, we examined the relationship between Big Five traits and generalized prejudice. Whereas previous research suggested that low levels of both Openness and Agreeableness are associated with prejudice against most types of groups (i.e., generalized prejudice; see Sibley \& Duckitt, 2008 for a meta-analytic review), these studies 
BIG FIVE AND GENERALIZED PREJUDICE 18

typically narrow the operationalization of generalized prejudice to disadvantaged, low status, and politically liberal targets. By adopting a broad operationalization of prejudice that considers prejudice against a heterogeneous set of target groups (consistent with definitions of prejudice; e.g., Aronson et al., 2010; Crandall et al., 2002), we address whether this is the case. Across four samples $(\mathrm{N}=7,543)$, we replicated existing findings when considering a narrow generalized prejudice limited to low status, disadvantaged, and liberal targets: both low Openness and low Agreeableness reliably predicted narrow generalized prejudice, with little role for the other three Big Five traits. The story changes, however, when we adopt a broad operationalization of generalized prejudice — only low Agreeableness was reliably related to prejudice toward a heterogeneous set of targets. Although other traits had significant associations, these effect sizes were substantially smaller and near zero. Thus, it appears that in regards to the Big Five traits, only people low in Agreeableness are prejudiced against most types of groups.

Adopting a broad operationalization of prejudice also allows us to test the second question: What types of people are prejudiced against certain types of groups? To do so, we tested several target group characteristics that the literature suggests may moderate relationships between personality and prejudice towards individual groups: perceived status, warmth, ideology, group choice, and assertiveness. We found a consistent moderating role of perceived ideology. It reliably moderated the relationships between prejudice and all Big Five traits except Agreeableness. Greater prejudice against more conservative targets was associated with high Openness, low Conscientiousness, low Extraversion, and high Neuroticism; greater prejudice against more liberal targets was associated with low Openness, high Conscientiousness, and low Neuroticism (high Extraversion was not necessarily associated with greater prejudice against more liberal targets, respectively, as the regression lines for this effect in Figure 2 is near zero at 
BIG FIVE AND GENERALIZED PREJUDICE 19

low/liberal levels of ideology). This moderation of the Openness-prejudice relationship conceptually replicates Brandt et al.’s (2015) finding that the openness-prejudice relationship is moderated by perceived conventionalism (perceived ideology and conventionalism have strong overlap; Brandt, 2017).

There was also a moderating role of perceived status, which moderated the relationships between prejudice and Extraversion and Agreeableness: Greater prejudice against high status targets was associated with low Extraversion, and greater prejudice against low status targets was associated with low Agreeableness (high Agreeableness and high Extraversion were not necessarily associated with greater prejudice against high status and low status targets, respectively, as the regression lines for these effects are near zero at these points). Finally, perceived choice, which is associated with perceived status (Keller, 2005), moderated the Agreeableness-prejudice relationship, such that low Agreeableness was associated with prejudice against lower choice targets (the regression line was near zero at high levels of perceived choice).

Two findings we considered a priori but that were not observed were moderation of the Agreeableness-prejudice relationship by warmth (in fact, the observed moderation was opposite the expected direction), and moderation of the Extraversion-prejudice relationship by perceived assertiveness (in fact, there was no clear effect). A few additional unexpected moderating effects emerged (i.e., assertiveness moderated the Openness-prejudice relationship; warmth moderated the Neuroticism-prejudice relationship), for which we did not have a priori predictions, and were small relative to the other moderating effects we observed. We refrain from further interpreting them here.

\section{Theoretical and Practical Implications}


BIG FIVE AND GENERALIZED PREJUDICE 20

Are some types of people prejudiced against most groups? In our study, we used a heterogeneous array of target groups, including a representative sample of groups (Sample 4), to form a measure of broad generalized prejudice. Prior research using a narrow operationalization of prejudice suggested that low Openness and Agreeableness orients people towards prejudice against most types of people. The present results do not support this assertion in regards to Openness, but they do in regards to Agreeableness. Any effects of Openness on prejudice have less to do with the nature of Openness as a personality trait conducive to prejudice, and more to do with the types of targets used in measures of generalized prejudice-namely, those who tend to be perceived as more liberal, and whom conservatives, who tend to lower in Openness, dislike (see also Brandt et al., 2015). Thus, the Openness-prejudice relationship appears driven by perceiver-target attitudinal (e.g., ideology) and/or trait (e.g., conventionalism) dissimilarity.

That said, the meta-analytic effect of Agreeableness on prejudice was robust and reliable, nearly identical across both narrow $(r=-.23)$ and broad $(r=-.25)$ generalized prejudice, and similar to that for narrow generalized prejudice observed in Sibley and Duckitt's (2008) metaanalysis $(r=-.22)$. This is not because people low in Agreeableness only dislike low status and disadvantaged groups, but rather because people low in Agreeableness dislike nearly everyone. Therefore, conclusions that low Agreeableness is related to narrow generalized prejudice (or, prejudice toward marginalized groups) is an artifact of Agreeableness’ relationship with disliking of other people in general. Although this relationship was moderated by perceived status, choice, and warmth, as mentioned above, it is more a case of degree of the relationship than direction of the relationship, as Figure 2 shows. Perceived social status, choice, and warmth may strengthen or weaken the relationship between Agreeableness and prejudice, but they do not reverse it in the way that perceived ideology reverses the relationships between Openness and Conscientiousness 
BIG FIVE AND GENERALIZED PREJUDICE 21

and prejudice (see, e.g., Figure 2, and Tables S2 - S5 for evidence of the remarkably consistent negative relationships between Agreeableness and prejudice against individual targets).

One possible explanation for the robust Agreeableness-prejudice relationship across groups is that people low in Agreeableness dislike everything. That is, the effects do not represent prejudice (i.e., negative affect based on group membership), but an unbridled negativity (e.g., Graziano et al., 2007, p. 566). Although practically speaking this is a distinction without a difference, we think that this is unlikely. Agreeableness was unassociated with “prejudice” (i.e., dislike) towards frogs and was even marginally related to more prejudice towards robots. Agreeableness may therefore be the single trait within the Big Five personality structure that determines people’s general orientation toward other people, whether positive (for those high in Agreeableness) or negative (for those low in Agreeableness), with some room for variation in the intensity of this relationship based on the group's social status, group choice, and warmth.

Are certain types of people prejudiced against certain types of groups? These results also suggest that Consistent with other work on Openness (Brandt et al., 2015) and cognitive ability (Brandt \& Crawford, 2016), one takeaway from the moderation tests is that personality can serve as a marker of dissimilarity. For instance, low Openness and high Conscientiousness are associated with greater conservatism, whereas high Openness and low Conscientiousness are associated with greater liberalism (Fatke, 2017; Hirsh, DeYoung, Xu, \& Peterson, 2010; Sibley \& Duckitt, 2008). Consistent with a dissimilarity-prejudice interpretation, we found that low Openness and high Conscientiousness were associated with prejudice against more liberal targets, whereas high Openness and low Conscientiousness were associated with prejudice against more conservative targets. 
BIG FIVE AND GENERALIZED PREJUDICE 22

Another takeaway is that perceived ideology and status were important to determining how different types of people evaluated groups that varied in these characteristics. Perceived ideology reliably moderated the relationship between prejudice and three personality traits (Openness, Conscientiousness, and Neuroticism), and perceived status reliably moderated the relationship between prejudice and two personality traits (Extraversion and Agreeableness). This finding provides indirect support for Koch et al.’s (2016) findings that ideology and status are important dimensions by which people perceive social groups. Given that people low in Agreeableness tend to be higher in social dominance orientation (Sibley \& Duckitt, 2008), it may be unsurprising that more disagreeable people express greater disliking of people, especially those low in social status (and group choice). That said, the mechanism that accounts for the moderating effect of status on the Extraversion-prejudice relationship is unclear. These findings more broadly speak to the importance of an interactionist perspective on the relationship between personality and prejudice - that is, there are qualities of the intergroup contexts that elicit prejudice among specific types of people.

Practical implications. Understanding what types of people are generally prejudiced versus what types of people are prejudiced toward particular types of groups not only has theoretical, but also practical implications. One possibility has to do with prejudice reduction interventions. If some types of prejudice are rooted in perceived dissimilarities (e.g., between those low in Openness and more liberal groups), then interventions that highlight superordinate identities may best reduce perceived dissimilarity and improve intergroup attitudes. However, prejudices among those low in Agreeableness may be less easy to stamp out because these are inherent to the perceiver him/herself, regardless of the social context. These results also suggest we can know which types of traits are risk factors for prejudice against certain types of groups 
BIG FIVE AND GENERALIZED PREJUDICE 23

(e.g., high Extraversion and low status groups) and develop appropriate responses. Recognizing that there are different types of prejudices associated with different personality types means that we need stronger theories of different types of (generalized) prejudices.

\section{What is Generalized Prejudice?}

This research illustrates that when speaking of generalized prejudice, researchers need to be specific about towards which groups the prejudice generalizes. We recognize that scientific terms are shorthand for more complex definitions and methodological choices. Just as theories may generalize reasonably far, but still have boundary conditions, so to some prejudices may generalize reasonably far and still have boundary conditions. It is important that these boundary conditions, however, are not glossed over nor forgotten in theoretical development. The entire theoretical space needs to be explored so that scholars know what is likely to predict prejudice towards which groups and why. Recent studies have shown that the typical generalized prejudice operationalization (what we call narrow generalized prejudice) generalizes to low status groups (Bergh et al., 2016). Our findings suggest that this may be the extent of its generalization. When including groups beyond low status groups, the findings for many personality factors change. Such narrow measures of generalized prejudice have adequate internal reliability, whereas broad measures such as the ones in our studies do not. However, that is in ways the point-narrow generalized prejudice measures only have good reliability because they are not generalizable.

One might see this set of results and argue that generalized prejudice should never be studied using the broad version that we studied here because this is never what generalized prejudice researchers really meant. We think that this is too restrictive. It is illustrative to include these heterogeneous arrays of groups to assess if Agreeableness and Openness are related to a “prejudiced personality” (in the case of Agreeableness) or just a “prejudice towards dissimilar 
BIG FIVE AND GENERALIZED PREJUDICE 24

groups” (in the case of, e.g., Openness). These are two different theoretical interpretations that cannot be teased apart by focusing on the narrow version. Others might see this same set of results and argue that given the broad nature of the original term (generalized prejudice), a measure of this construct should assume maximal generalization and so broad generalized prejudice is the only correct way forward. We think that this is also too restrictive. Indeed, it may be the case that there are multiple generalized prejudices that only generalize to subsets of target groups (e.g., low status groups, conservative groups, progressive groups etc.). These more specific generalized prejudices are also (potentially) prejudices that generalize, but in a more limited way than the broad generalized prejudice we focused on. That is, rather than developing a theory of generalized prejudice, this paper may be seen as the first step in developing a theory of generalized prejudices.

\section{Limitations and Future Directions}

This research represents an important first step in identifying the personality factors associated with broad generalized prejudice, and the group characteristics that may strengthen, weaken, or even reverse relationships between personality and prejudice. In addition to the standard calls for replications with additional samples, future research should seek to understand some of the gaps that still exist. Sample 1 utilized a list of targets included in a nationally representative sample, the lists of targets for Samples 2 and 3 were chosen for their ideological heterogeneity because this has proven to be an important factor in prior studies (see e.g., Chambers et al., 2013), and the groups used in Sample 4 were selected based on groups generated by participants in a bottom-up fashion (Koch et al., 2016). Although this was a broad array of 39 groups, we did not include all possible groups, nor groups where prejudice is highly normative (e.g., pedophiles) or counter-normative (e.g., children; see Crandall et al., 2002). 
BIG FIVE AND GENERALIZED PREJUDICE 25

Whereas the Big Five has been the dominant model of personality for decades, other evidence suggests a six-factor personality space represented by the HEXACO model (Ashton, Lee, \& de Vries, 2014). The Extraversion and Openness dimensions are roughly similar in the Big Five and HEXACO models, whereas Agreeableness in the HEXACO model contains an anger component typically associated with Neuroticism in the Big Five. Further, the HonestyHumility factor (e.g., honest and sincere vs. greedy and deceitful) has items that are peripheral to the Agreeableness factor as identified in the Big Five. Given the importance of the Big Five Agreeableness factor in predicting generalized prejudice as revealed in the present studies, it may be useful to examine whether a HEXACO approach that conceptualizes the Agreeableness factor (and related Honesty-Humility factor) differently may provide a more nuanced understanding of the personality traits associated with generalized prejudice. This seems likely as some work using the HEXACO approach finds that the Honesty-Humility factor predicts narrow generalized prejudice and Agreeableness does not (Bergh et al., 2016).

\section{Conclusion}

Previous research has used a narrow operationalization of generalized prejudice exclusive to attitudes toward socially disadvantaged, low status, and liberal target groups. Meta-analyses of this literature have concluded that low levels of Openness and Agreeableness are associated with generalized prejudice, whereas the other three Big Five dimensions are not (Akrami et al., 2011; Sibley \& Duckitt, 2008). By using a broad operationalization of prejudice including targets from across the societal and political spectrums, we address what types of people will express prejudice toward most types of groups, and what types of people will express prejudice toward certain types of groups. Our findings challenge extant conclusions. Whereas Openness is practically unrelated to broad generalized prejudice, low Agreeableness is consistently and 
BIG FIVE AND GENERALIZED PREJUDICE 26

robustly related to broad generalized prejudice. Whereas the effects of Openness (and to an extent, Conscientiousness) may be explained by ideological worldview conflict, Agreeableness seems to generally orient people toward a negative evaluation of others, especially those low in social status and group choice. Importantly, conclusions that low Agreeableness is related to narrow generalized prejudice (or, prejudice toward marginalized groups) are an artifact of Agreeableness' relationship with a general dislike of other people. These findings promise to aid the development of theories of generalized prejudices. 


\section{References}

Adorno, T. W., Frenkel-Brunswick, E., Levinson, D. J., \& Sanford, R. N. (1950). The authoritarian personality. New York: Harper.

Akrami, N., Ekehammar, B., \& Bergh, R. (2011). Generalized prejudice: common and specific components. Psychological Science, 22, 57-59.

Akrami, N., Ekehammar, B., Bergh, R., Dahlstrand, E., \& Malmsten, S. (2009). Prejudice: The person in the situation. Journal of Research in Personality, 43, 89-897.

Allport, G. W. (1954). The nature of prejudice. Reading, MA: Addison-Wesley.

Aronson, E., Wilson, T. D., \& Akert, R. M. (2010). Social Psychology (7 $\left.7^{\text {th }}\right)$. New York: Prentice Hall.

Ashton, M. C., Lee, K., \& de Vries, R. (2014). The HEXACO honesty-humility, agreeableness, and emotionality factors: A review of research and theory. Personality and Social Psychology Review, 18, 139-152.

Bergh, R., Akrami, N., \& Ekehammar, B. (2012). The personality underpinnings of explicit and implicit generalized prejudice. Social Psychological and Personality Science, 3, 614-621.

Bergh, R., Akrami, N., Sidanius, J., \& Sibley, S. (2016). Is group membership necessary for understanding generalized prejudice? A re-evaluation of why prejudices are interrelated. Journal of Personality and Social Psychology, 111, 367-395.

Brandt, M. J. (2017). Predicting ideological prejudice. Psychological Science, 28, 712-722.

Brandt, M. J., Chambers, J. R., Crawford, J. T., Wetherell, G., \& Reyna, C. (2015). Bounded openness: The effect of openness to experience on intolerance is moderated by target group conventionality. Journal of Personality and Social Psychology, 109, 549-568. 
BIG FIVE AND GENERALIZED PREJUDICE 28

Brandt, M. J., \& Crawford, J. T. (2016). Answering unresolved questions about the relationship between cognitive ability and prejudice. Social Psychological and Personality Science, 7, 884-892.

Brandt, M. J. \& Proulx, T. (2016). Conceptual creep as a human (and scientific) goal. Psychological Inquiry, 27, 18-23.

Brandt, M. J., Reyna, C., Chambers, J., Crawford, J., \& Wetherell, G. (2014). The ideologicalconflict hypothesis: Intolerance among both liberals and conservatives. Current Directions in Psychological Science, 23, 27-34.

Brandt, M. J. \& van Tongeren, D. R. (in press). People both high and low on religious fundamentalism are prejudiced towards dissimilar groups. Journal of Personality and Social Psychology.

Brown, R. (2010). Prejudice: Its Social Psychology (2nd ed.). Malden, MA: Wiley-Blackwell.

Byrne, D. (1969). Attitudes and attraction. In Advances in experimental social psychology (Vol. 4, pp. 35-89). Academic Press.

Carney, D. R., Jost, J. T., Gosling, S. D., \& Potter, J. (2008). The secret lives of liberals and conservatives: Personality profiles, interaction styles, and the things they leave behind. Political Psychology, 29(6), 807-840.

Chambers, J. R., Schlenker, B. R., \& Collisson, B. (2013). Ideology and prejudice: The role of value conflicts. Psychological Science, 24, 140-149.

Correll, J., Judd, C. M., Park, B., \& Wittenbrink, B. (2010). Measuring prejudice, stereotypes and discrimination. In J. F. Dovidio, M. Hewstone, P. Glick, \& V. M. Esses (Eds.), The SAGE Handbook of Prejudice, Stereotyping and Discrimination (pp. 45-62). Thousand Oaks, CA: SAGE. 
BIG FIVE AND GENERALIZED PREJUDICE 29

Costa, P. T., \& McCrae, R. R. (1985). The NEO personality inventory manual. Odessa, FL: Psychological Assessment Resources.

Crandall, C. S., Eshleman, A., \& O'Brien, L. (2002). Social norms and the expression and suppression of prejudice: the struggle for internalization. Journal of Personality and Social Psychology, 82, 359-378.

Crawford, J. T. (2014). Ideological symmetries and asymmetries in political intolerance and prejudice toward political activist groups. Journal of Experimental Social Psychology, 55, 284-298.

Crawford, J.T., Brandt, M. J., Inbar, Y., Chambers, J.R., \& Motyl, M. (in press). Social and economic ideologies differentially predict prejudice across the political spectrum, but social issues are most divisive. Journal of Personality and Social Psychology.

Crawford, J. T., Inbar, Y., \& Maloney, V. (2014). Disgust sensitivity selectively predicts attitudes toward groups that threaten (or uphold) traditional sexual morality. Personality and Individual Differences, 70, 218-223.

Crawford, J. T., \& Pilanski, J. M. (2014). Political intolerance, right and left. Political Psychology, 35, 841-851.

Crawford, J. T. (2018). The politics of the psychology of prejudice. In J. T. Crawford \& L. Jussim (Eds.), The Politics of Social Psychology (pp. 99-115). New York: Routledge.

Cuddy, A. J., Fiske, S. T., \& Glick, P. (2008). Warmth and competence as universal dimensions of social perception: The stereotype content model and the BIAS map. Advances in Experimental Social Psychology, 40, 61-149. 
BIG FIVE AND GENERALIZED PREJUDICE 30

Duckitt, J., \& Sibley, C. G. (2007). Right wing authoritarianism, social dominance orientation and the dimensions of generalized prejudice. European Journal of Personality, 21(2), 113-130.

Ekehammar, B., \& Akrami, N. (2003). The relation between personality and prejudice: A variable- and a person-centred approach. European Journal of Personality, 17, 449-464.

Ekehammar, B., \& Akrami, N. (2007). Personality and prejudice: From Big Five personality factors to facets. Journal of Personality, 75, 899-926.

Ekehammar, B., Akrami, N., Gylje, M., \& Zakrisson, I. (2004). What matters most to prejudice: Big Five personality, social dominance orientation, or right-wing authoritarianism? European Journal of Personality, 18, 463-482.

Fatka, M. (2017). Personality traits and political ideology: A first global assessment. Political Psychology, 38, 881-899.

Fiske, S. T., Cuddy, A. J., Glick, P., \& Xu, J. (2002). A model of (often mixed) stereotype content: competence and warmth respectively follow from perceived status and competition. Journal of Personality and Social Psychology, 82, 878-902.

Flynn, F. J. (2005). Having an open mind: The impact of openness to experience on interracial attitudes and impression formation. Journal of Personality and Social Psychology, 88, 816-826.

Gosling, S. D., Rentfrow, P. J., \& Swann Jr, W. B. (2003). A very brief measure of the Big-Five personality domains. Journal of Research in Personality, 37, 504-528.

Graziano, W. G., Bruce, J., Sheese, B. E., \& Tobin, R. M. (2007). Attraction, personality, and prejudice: Liking none of the people most of the time. Journal of Personality and Social Psychology, 93, 565-582. 
BIG FIVE AND GENERALIZED PREJUDICE 31

Gray, H. M., Gray, K., \& Wegner, D. M. (2007). Dimensions of mind perception. Science, 315(5812), 619.

Hirsh, J. B., DeYoung, C. G., Xu, X., \& Peterson, J. B. (2010). Compassionate liberals and polite conservatives: Associations of agreeableness with political ideology and moral values. Personality and Social Psychology Bulletin, 36, 655-664.

Hodson, G., \& Dhont, K. (2015). The person-based nature of prejudice: Individual difference predictors of intergroup negativity. European Review of Social Psychology, 26, 1-42.

Jayaratne, T. E., Ybarra, O., Sheldon, J. P., Brown, T. N., Feldbaum, M., Pfeffer, C. A., \& Petty, E. M. (2006). White Americans’ genetic lay theories of race differences and sexual orientation: Their relationship with prejudice toward blacks, and gay men and lesbians. Group Processes \& Intergroup Relations, 9, 77-94.

John, O. P., \& Srivastava, S. (1999). The Big Five trait taxonomy: History, measurement, and theoretical perspectives. In L. A. Pervin \& O. P. John (Eds.), Handbook of personality: Theory and research (2nd ed., pp. 102-138). New York: Guilford.

Judd, C. M., Westfall, J., \& Kenny, D. A. (2012). Treating stimuli as a random factor in social psychology: A new and comprehensive solution to a pervasive but largely ignored problem. Journal of Personality and Social Psychology, 103, 54-69.

Kammrath, L. K., \& Scholer, A. A. (2011). The Pollyanna myth: How highly agreeable people judge positive and negative relational acts. Personality and Social Psychology Bulletin, 37, 1172-1184.

Keller, J. (2005). In genes we trust: The biological component of psychological essentialism and its relationship to mechanisms of motivated social cognition. Journal of Personality and Social Psychology, 88, 686-702. 
Koch, A., Imhoff, R., Dotsch, R., Unkelbach, C., \& Alves, H. (2016). The ABC of stereotypes about groups: Agency/socioeconomic success, conservative-progressive beliefs, and communion. Journal of Personality and Social Psychology, 110, 675-709.

Marcus, G. E., Sullivan, J. L., Theiss-Morse, E., \& Wood, S. L. (1995). With malice toward some: How people make civil liberties judgments. Cambridge University Press.

Parks-Leduc, L., Feldman, G., \& Bardi, A. (2014). Personality traits and personal values: A meta-analysis. Personality and Social Psychology Review, 19, 3-29.

Sibley, C. G., \& Duckitt, J. (2008). Personality and prejudice: A meta-analysis and theoretical review. Personality and Social Psychology Review, 12, 248-279.

Sidanius, J., \& Pratto, F. (1999). Social dominance: An intergroup theory of social hierarchy and oppression. New York: Cambridge University Press.

Suhay, E., Brandt, M. J., \& Proulx, T. (2017). Lay belief in biopolitics and political prejudice. Social Psychological and Personality Science, 8(2), 173-182

Van Hiel, A., \& Mervielde, I. (2004). Openness to experience and boundaries in the mind: Relationships with cultural and economic conservative beliefs. Journal of Personality, 72(4), 659-686.

Viechtbauer, W. (2010). Conducting meta-analyses in R with the metafor package. Journal of Statistical Software, 36, 1-48.

Weiner, B. (1995). Judgments of responsibility: A foundation for a theory of social conduct. New York: Guilford Press.

Weiner, B., Perry, R. P., \& Magnusson, J. (1988). An attributional analysis of reactions to stigmas. Journal of Personality and Social Psychology, 55, 738-748. 
Wetherell, G., Brandt, M. J., \& Reyna, C. (2013) Discrimination across the ideological divide: The role of perceptions of value violations and abstract values in discrimination by liberals and conservatives. Social Psychological and Personality Science, 4, 658-667.

Williams, M. J., \& Eberhardt, J. L. (2008). Biological conceptions of race and the motivation to cross racial boundaries. Journal of Personality and Social Psychology, 94, 1033-1047.

Yarkoni, T., Ashar, Y.K., \& Wager, T. D. (2015). Interactions between donor Agreeableness and recipient characteristics in predicting charitable donation and positive social evaluation. PeerJ 3:e1089 https://doi.org/10.7717/peerj.1089 
Table 1

Moderators of the personality-prejudice relationships across Samples 1 - 4

\begin{tabular}{|c|c|c|c|c|}
\hline & \multicolumn{2}{|c|}{ Openness-Prejudice } & \multicolumn{2}{|c|}{ Conscientiousness-Prejudice } \\
\hline & $r$ & $\beta$ & $r$ & $\beta$ \\
\hline Status & $.40 * * *$ & $-.20 * *$ & $-.42 * * *$ & -0.22 \\
\hline Warmth & $-.42 * * *$ & 0.09 & -0.06 & $-.29 *$ \\
\hline Ideology & $.92 * * *$ & $.91 * * *$ & $-.48 * * *$ & $-.48 * * *$ \\
\hline Choice & $.38 * *$ & 0.02 & 0.01 & 0.16 \\
\hline \multirow[t]{3}{*}{ Assertiveness } & $.53 * * *$ & $.29 * *$ & -0.2 & -0.15 \\
\hline & & ersion-Prejudice & & bleness-Prejudice \\
\hline & $r$ & $\beta$ & $r$ & $\beta$ \\
\hline Status & $-.58 * * *$ & $-.35^{*}$ & $.28^{*}$ & $.45 * * *$ \\
\hline Warmth & 0.09 & $-0.29 *$ & $-.44 * * *$ & $-.37 * * *$ \\
\hline Ideology & $-.51 * * *$ & $-.36 * *$ & -0.03 & $-.40 * * *$ \\
\hline Choice & -0.2 & 0.12 & $.58 * * *$ & $.51 * * *$ \\
\hline \multirow[t]{3}{*}{ Assertiveness } & $-.41 * * *$ & -0.27 & $.38 * * *$ & $-.36 * *$ \\
\hline & & icism-Prejudice & & \\
\hline & $r$ & $\beta$ & & \\
\hline Status & $.40 * * *$ & 0.24 & & \\
\hline Warmth & $-.35 * *$ & $-.32 *$ & & \\
\hline Ideology & $.59 * * *$ & $.45 * * *$ & & \\
\hline Choice & 0.17 & -0.03 & & \\
\hline Assertiveness & $.33^{* *}$ & -0.18 & & \\
\hline
\end{tabular}

Note. Bivariate correlation coefficients are those between the characteristic and the partial correlation between the Big Five trait and prejudice. Multivariate coefficients are standardized regression coefficients for the partial correlation between the Big Five trait and prejudice regressed on all five characteristics and the dummy-coded sample variables. Coefficients in bold are those that suggest suppression effects. 
Figure 1

Forest plots of partial correlations between the Big Five traits and narrow (left-most panel) and broad (right-most panel) generalized prejudice.

\begin{tabular}{lll} 
Samples & [95\% Cl] \\
\hline Agreeableness \\
Sample 1 \\
Sample 2 \\
Sample 3 \\
Sample 4 \\
Agreeableness Model \\
Conscientiousness \\
Sample 1 \\
Sample 2 \\
Sample 3 \\
Sample 4 \\
Conscientiousness Model \\
Extraversion \\
Sample 1 \\
Sample 2 \\
Sample 3 \\
Sample 4 \\
Extraversion Model
\end{tabular}

Personality - Narrow Generalized Prejudice Partial Correlation (pr)

\begin{tabular}{lll} 
Samples & [95\% Cl] \\
\hline Agreeableness \\
Sample 1 \\
Sample 2 \\
Sample 3 \\
Sample 4 \\
Agreeableness Model \\
Conscientiousness \\
Sample 1 \\
Sample 2 \\
Sample 3 \\
Sample 4 \\
Conscientiousness Model \\
Extraversion
\end{tabular}

Personality - Broad Generalized Prejudice Partial Correlation (pr)

Note. Error bars are 95\% confidence intervals. 
BIG FIVE AND GENERALIZED PREJUDICE 36

Figure 2

Moderation of personality-prejudice relationships by target group characteristics, Samples 1 - 4
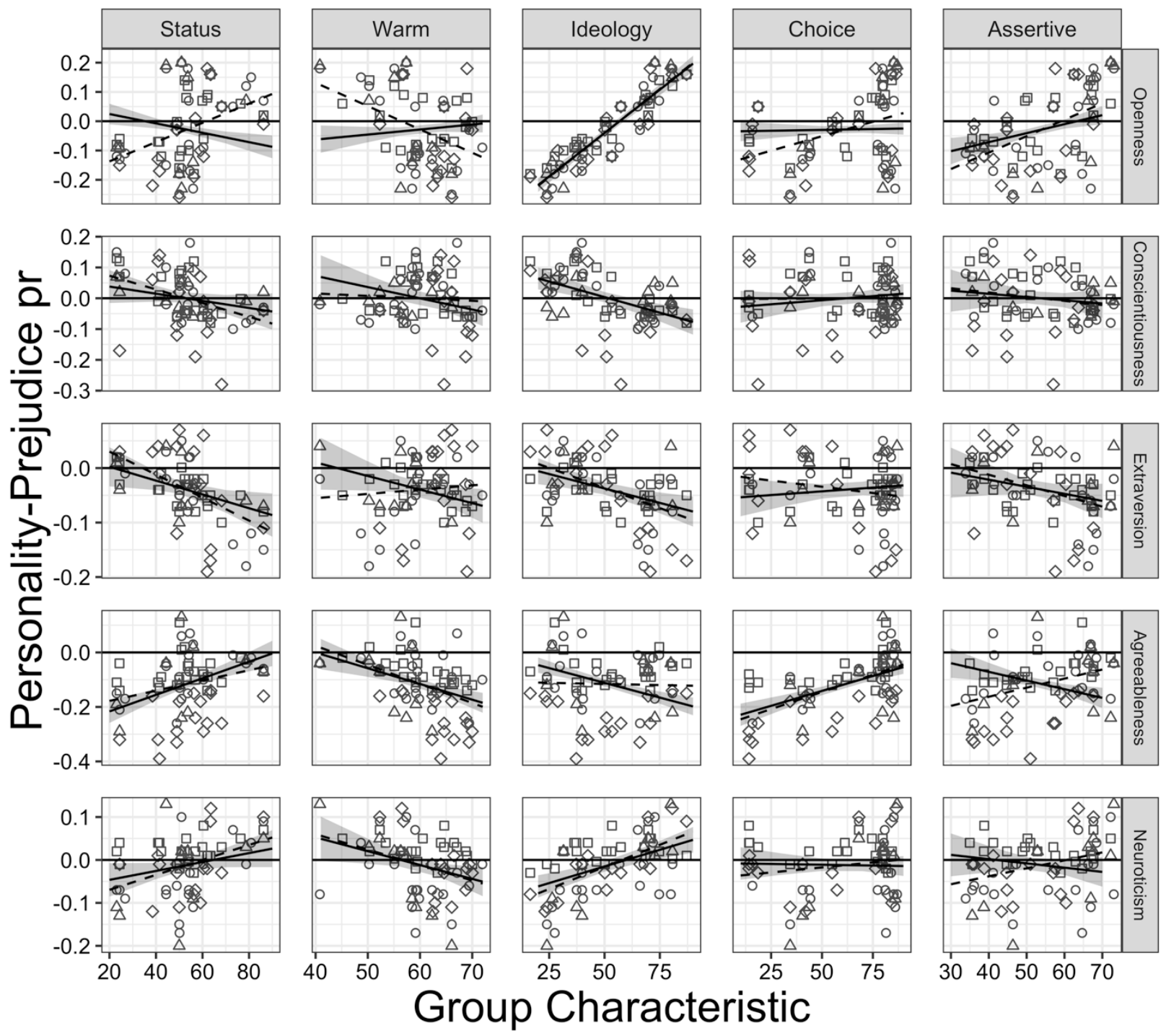

\section{Group Characteristic}

Model Type

\section{- With Covariates - - Without Covariates}

Study

$$
\square \quad 1 \circ 2 \diamond 3 \diamond 4
$$

Note. The dashed regression line is the linear relationship between the two variables. The solid regression line is the linear relationship between the two variables when controlling for the other group characteristics and the study. The gray region around the line is the $95 \%$ confidence interval of this latter regression line. 